\section{NEW DENTAL TEACHING UNIT FIRST FOR WALES}

First Minister of Wales Rhodri Morgan has officially unveiled a new state of the art dental teaching unit in Porth, the first of its kind to open in Wales.

The multi-purpose unit is funded as a joint initiative by the Welsh Assembly Government, Rhondda Cynon Taff Teaching Local Health Board and the School of Postgraduate Medical and Dental Education within Cardiff University.

The dental teaching unit will be home to ten recently qualified dentists while they complete a two year longitudinal dental foundation training scheme. A central decontamination unit has been installed in the building to improve infection control, while cutting edge technology has been imported from America and used to fully equip eight dental surgeries.

The newly qualified dentists will work under the guidance of experienced dental surgeons and will benefit from versatile working stations, which allow the dentist to work ambidextrously with their equipment. Electronic charting and digital imaging systems will also save valuable time for both dentists and patients, enabling more patients to receive comprehensive care in all aspects of NHS dentistry.

The dental teaching unit also features an air-conditioned conference centre with 120 seating capacity. A large screen linked to video cameras located in one of the surgeries will allow members of the dental team to watch live procedures. After viewing the procedures they can enhance and develop their own skills in a specialised dental training room fully equipped with 18 individual work stations (phantom heads).

On opening the unit, First Minister Rhodri Morgan said, 'This dental training unit will be the first of its kind in Wales and it will make a significant difference to the quality of our den- tistry. Not only will it provide invaluable training for our future and current dentists, it will improve access to dentistry in the area so that every patient will have access to a dentist.'

The surgery is also equipped with a surgical operating microscope allowing extreme close up images of the root canal systems of teeth. Mr Jeremy Hayes, Senior Dental Surgeon, will use this microscope to provide specialist endodontic treatment for patients of the dental teaching unit along with referrals from local practitioners under the terms of the NHS dental services.
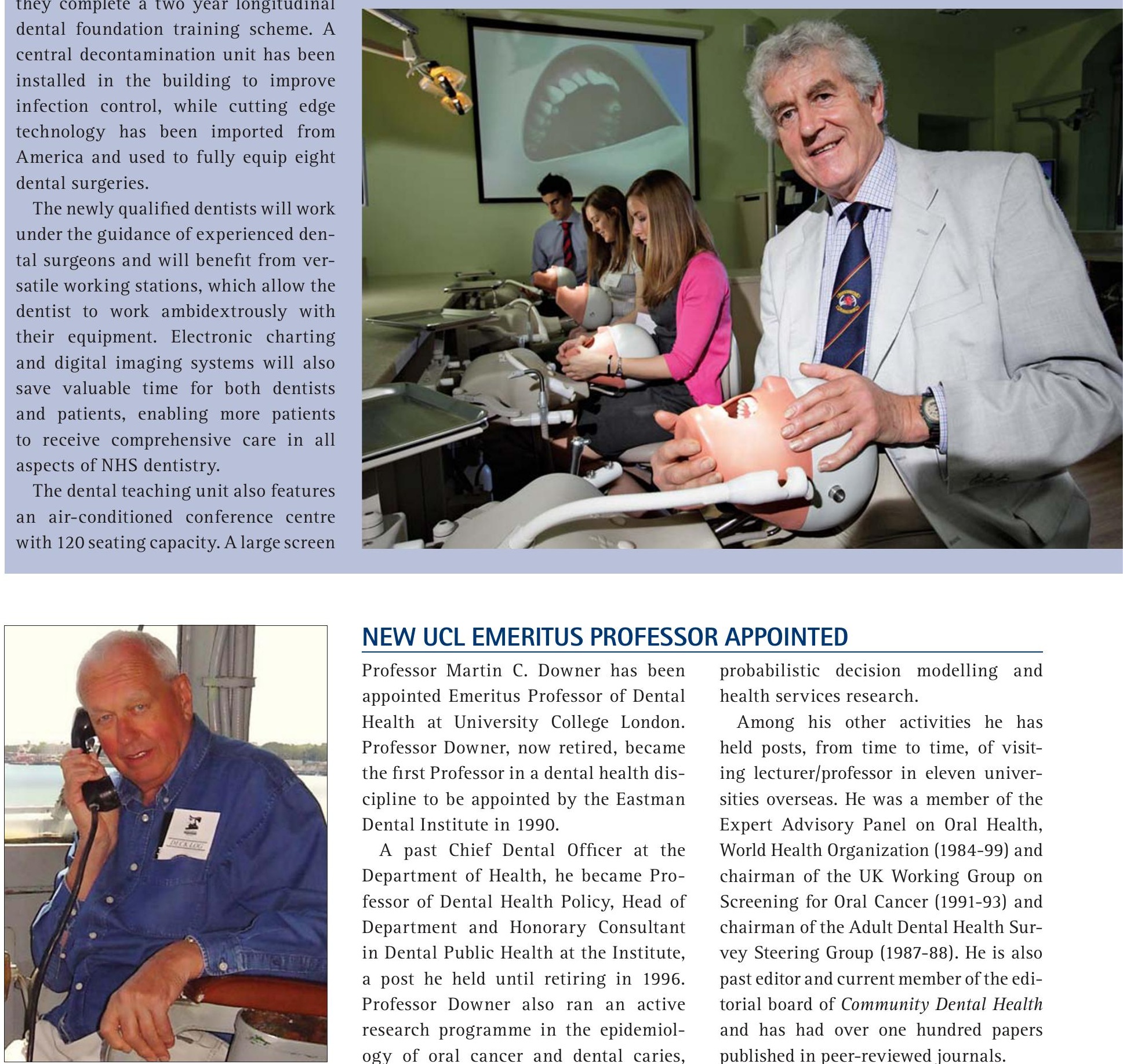

\title{
NEW UCL EMERITUS PROFESSOR APPOINTED
}

Professor Martin C. Downer has been appointed Emeritus Professor of Dental Health at University College London. Professor Downer, now retired, became the first Professor in a dental health discipline to be appointed by the Eastman Dental Institute in 1990.

A past Chief Dental Officer at the Department of Health, he became Professor of Dental Health Policy, Head of Department and Honorary Consultant in Dental Public Health at the Institute, a post he held until retiring in 1996. Professor Downer also ran an active research programme in the epidemiology of oral cancer and dental caries, probabilistic decision modelling and health services research.

Among his other activities he has held posts, from time to time, of visiting lecturer/professor in eleven universities overseas. He was a member of the Expert Advisory Panel on Oral Health, World Health Organization (1984-99) and chairman of the UK Working Group on Screening for Oral Cancer (1991-93) and chairman of the Adult Dental Health Survey Steering Group (1987-88). He is also past editor and current member of the editorial board of Community Dental Health and has had over one hundred papers published in peer-reviewed journals. 